\title{
The Association of Surgical Margins and Local Recurrence in Women with Early-Stage Invasive Breast Cancer Treated with Breast-Conserving Therapy: A Meta-Analysis
}

\author{
Nehmat Houssami, MD, PhD ${ }^{1}$, Petra Macaskill, $\mathbf{P h D}^{1}$, M. Luke Marinovich, MPH ${ }^{1}$, and Monica Morrow, MD $^{2}$ \\ ${ }^{1}$ Screening and Test Evaluation Program (STEP), School of Public Health (A27), Sydney Medical School, University of \\ Sydney, Sydney, Australia; ${ }^{2}$ Breast Service, Department of Surgery, Memorial Sloan Kettering Cancer Center, New York, \\ NY
}

\begin{abstract}
Purpose. There is no consensus on what constitutes adequate negative margins in breast-conserving therapy (BCT). We systematically review the evidence on surgical margins in BCT for invasive breast cancer to support the development of clinical guidelines.

Methods. Study-level meta-analysis of studies reporting local recurrence (LR) data relative to final microscopic margin status and the threshold distance for negative margins. LR proportion was modeled using random-effects logistic meta-regression.

Results. Based on 33 studies (LR in 1,506 of 28,162), the odds of LR were associated with margin status [model 1: odds ratio (OR) 1.96 for positive/close vs negative; model 2: OR 1.74 for close vs. negative, 2.44 for positive vs. negative; $(P<0.001$ both models $)]$ but not with margin distance [model 1: $>0 \mathrm{~mm}$ vs. $1 \mathrm{~mm}$ (referent) vs. $2 \mathrm{~mm}$ vs. $5 \mathrm{~mm}(P=0.12)$; and model $2: 1 \mathrm{~mm}$ (referent) vs. $2 \mathrm{~mm}$ vs. $5 \mathrm{~mm}(P=0.90)$ ], adjusting for study median follow-up time. There was little to no statistical evidence that the odds of LR decreased as the distance for declaring negative margins increased, adjusting for follow-up time [model 1: $1 \mathrm{~mm}$ (OR 1.0, referent), $2 \mathrm{~mm}$ (OR 0.95), $5 \mathrm{~mm}$ (OR 0.65), $P=0.21$ for trend; and model 2: $1 \mathrm{~mm}$ (OR 1.0, referent), $2 \mathrm{~mm}$ (OR 0.91), $5 \mathrm{~mm}$ (OR 0.77),
\end{abstract}

Electronic supplementary material The online version of this article (doi:10.1245/s10434-014-3480-5) contains supplementary material, which is available to authorized users.

(C) Society of Surgical Oncology 2014

First Received: 6 September 2013;

Published Online: 29 January 2014

N. Houssami, MD, PhD

e-mail: nehmat.houssami@sydney.edu.au
$P=0.58$ for trend]. Adjustment for covariates, such as use of endocrine therapy or median-year of recruitment, did not change the findings.

Conclusions. Meta-analysis confirms that negative margins reduce the odds of LR; however, increasing the distance for defining negative margins is not significantly associated with reduced odds of LR, allowing for follow-up time. Adoption of wider relative to narrower margin widths to declare negative margins is unlikely to have a substantial additional benefit for long-term local control in BCT.

Both tumour burden and tumour biology contribute to clinical outcomes in breast cancer (BC). The effectiveness of breast-conserving therapy (BCT) [breast-conserving surgery (BCS) and radiation therapy] for local treatment of invasive $\mathrm{BC}$ is well established. ${ }^{1-6}$ Adequate local control has been shown to confer a survival benefit at long-term follow-up. ${ }^{6}$ BCS aims to achieve a balance between complete resection of the tumour and to avoid excessive resection of breast tissue to provide good cosmetic outcome. ${ }^{7,8}$ Many tumour and therapeutic factors influence the risk of local (in-breast) recurrence (LR) after BCT for invasive $\mathrm{BC}$, including the status of surgical margins. ${ }^{6-12}$

There is consensus that the risk of LR is increased if the surgical margins are positive (ink on tumour cells at the resection margin), although estimates of effect vary between studies. ${ }^{8,10,12,13}$ However, to date, there is no consensus on what constitutes an adequate negative margin for BCS. ${ }^{12-17}$ Lack of consensus on this issue is reflected in variations in practice amongst clinicians, countries, and clinical guidelines, with the net result that reexcision to achieve more widely clear margins is commonly performed. ${ }^{11,17-20}$

In this work, we extend our previous systematic review on margins to provide an updated summary of the evidence 
on the association between tumour margins in invasive $\mathrm{BC}$ and LR, to support the development of consensus guidelines. ${ }^{10}$ Using study-level meta-analysis, the evidence on surgical margins in women with early-stage invasive $\mathrm{BC}$ treated with BCT was systematically examined (a) to estimate the effect of microscopic margin status on LR, (b) to examine the effect of various thresholds to define negative (and relative positive or close) margins, and (c) to discuss whether a minimum negative distance or width can be defined for margins in relation to maximising local control.

\section{METHODS}

The methodology used in this systematic review was based on published work from Houssami et al. ${ }^{10}$ and will be described relatively briefly.

\section{Criteria for Study Eligibility}

Studies were eligible for inclusion if they reported data allowing calculation of the proportion of $L R$ in relation to margin status and the threshold width or distance used to declare a negative margin, and where the following predefined criteria also were met $^{10}$ : (1) subjects had earlystage invasive BC (clinical or pathological stages I and II in at least $90 \%$ ); (2) treatment consisted of BCT [BCS and whole-breast radiotherapy (WBR)]; (3) reported quantitatively-defined microscopic margins where negative margins, and relatively positive and/or close margins, were defined in terms of a threshold distance or width from the cut edge of the specimen (exception noted below); (4) provided age data; and (5) had a minimum median or mean follow-up time of 4 years.

Studies reporting LR without quantifying margins, or where all subjects had the same margin status, or using nonstandard or unclear margin definitions, or limited to small subgroups, were ineligible. For the updated metaanalysis, we also considered studies that did not declare a quantified distance for negative margins (hence not meeting criterion number 3 ) provided that the information in the study allowed classification of negative margins as $>0 \mathrm{~mm}$; however, these studies were not included in trend analysis for negative margin distance. Authors were contacted for clarification or for further information on definitions and/or data where necessary.

Study eligibility criteria considered epidemiological principles in evaluating prognostic studies-specifically, that subjects were assembled at a relatively common point in the course of disease and that adequate follow-up time was allowed for clinical endpoints to have occurred. ${ }^{10,21,22}$ Therefore, eligibility criteria for this review integrated cancer stage and a minimum follow-up time as a quality filter and required final microscopic margins and WBR as inclusion criteria to reflect standards of care. Additional information to help characterize and appraise eligible studies was extracted, including design, population characteristics, follow-up, margin assessment, and treatmentrelated variables. These were partly adapted from a framework and recommendations for assessing the internal validity of studies dealing with prognosis in metaanalysis. $^{21,22}$

\section{Literature Search and Data Extraction}

A systematic literature search was conducted [MEDLINE and EBM reviews, 1965 to May 2010 (initial search); Medline search updated at January 2013] for primary studies that met eligibility criteria, using the search and study identification strategy summarised in OnlineAppendix 1. One investigator $(\mathrm{NH})$ screened abstracts identified in the literature search $(n=870)$ and full-text of potentially relevant studies $(n=115)$. Data from eligible studies $(n=33)$ were extracted independently by two investigators (NH, MLM for updated data extraction; or as previously described) using predefined data forms. ${ }^{10,23-55}$ The search strategy and identification of eligible studies (including information on related studies and excluded studies) are presented in Online-Appendix $1 .^{56-89}$ Where two or more papers reported the same cohort, the most recent study (that provided margin-specific LR data) was preferentially used to minimize duplicate data-additional details in Online-Appendix 1.

\section{Extracted Variables}

Descriptive and quantitative data were extracted from each study for the following: margin definition and categories, LR definition and outcomes data, duration of (and losses to) follow-up, years of study recruitment, study design, age, stage (distribution, node status, aggregate tumour size), surgery including reexcision, radiation therapy [WBR dose, boost (proportion given boost and dose), total dose to tumor bed, node irradiation], systemic therapy (endocrine or chemotherapy use), hormone receptors, tumor grade, lymphovascular invasion (LVI), and extensive intraductal component (EIC). We did not collect the following variables (HER2 status, histology distribution) because our prior data extractions indicated that few studies reported these variables.

\section{Definitions of Variables}

Margins Study-specific information on the definition of the final microscopic margins, from excision or reexcision, was extracted based on margin status (whether negative, 
close, or positive) and margin distance (the width used as the threshold for declaring negative margins relative to positive or close). To standardize synthesis of the evidence on microscopic margins, we considered a standard classification for positive margins to be the presence of (invasive or in situ) cancer at the transected or inked margin. Negative margins were defined as the absence of tumour within a specified distance $(\mathrm{mm})$ of the resection margin, with a close margin indicating presence of tumour within that distance but not at the resection margin. Studies reporting margin distance for negative relative to positive (without differentiating close from positive) also were considered. To allow for variable classification of margins across studies, two models were developed (see also "Statistical Analysis" section): model 1 included all studies, combining positive and close (because some studies did not distinguish between these categories or did not report LR data separately for positive and close) compared with negative; and model 2 included studies allowing comparisons across the three categories positive, close and negative.

Where an unknown margin category was reported, this was generally due to: specimen not being inked, specimen fragmented or removed in pieces; microscopic margins not given in the pathology report; or specimen not available (in studies where specimens were reviewed). ${ }^{38,40,42,47,49}$ Because the unknown category cannot contribute meaningful data on the effect of margins, it has not been included in our models however data for this category were included in descriptive analyses.

Local Recurrence Definition and data for LR as endpoint was classified into two categories: $L R$ (first), for studies reporting LR as the first site of relapse (including studies where LR may have occurred alone or simultaneously with regional and/or distant relapse); and $L R$ (any), for studies reporting LR occurring at any time (including LR as the first site of relapse or concurrent with or after regional or distant relapse, or LR not further specified).

Covariates Extracted variables were classified based on quantitative data; additional information was categorized for stage, surgery, and losses to follow-up, for analytic purposes. Studies were classified into two categories for stage: (1) all subjects had stage I-II BC; or (2) $\geq 90 \%$ of subjects were estimated to have had stage I-II BC, based on reported stagedistribution, or derived from tumor-size and node data distribution. Therefore, category 2 studies included some stage 0 (DCIS), stage III, or stage unknown in $<10 \%$ of subjects. Studies reporting quadrantectomy in some subjects also were examined separately. ${ }^{32,35,38,40,41,43,48,50,54}$ Studies reporting information on losses to follow-up were compared with those not reporting any information on this variable.
Statistical Analysis

Descriptive analyses were used to examine the distribution of study-level variables. For continuous measures, the median, range, and interquartile range (IQR) were calculated. The proportion of women who had a LR was modeled using random effects logistic meta-regression. Random study effects were included in all models to allow for anticipated heterogeneity between studies beyond what would arise from within study sampling error alone. Taking account of both within, and between study variability provides valid standard errors, confidence intervals, and $P$ values. Statistical significance was set at $P<0.05$ (twosided); $P<0.1$ was considered as weak evidence of association for analysis of covariates (see below).

Modeling was used to assess whether the odds of LR were associated with margin status and distance, adjusted for study-specific median follow-up time (given that risk of LR is known to increase with longer follow-up time and based on evidence of association in our prior and present meta-analysis). Margin status and distance were tested for interaction. Each covariate was fitted both univariately (in a model that did not include margins) and also jointly with margin status and distance, and study median follow-up time (adjusted models). Study-specific median age and median follow-up time were fitted as continuous variables. Covariates that showed at least a weak association $(P<0.1)$ with LR either univariately or in the adjusted models were further examined and reported in the models; LR type also was included in modeling based on clinical relevance. Covariates reported in less than half of studies were not considered reliable for modeling.

In Model 1, margin status was fitted as a dichotomous variable (positive/close vs negative) and distance was fitted as a categorical variable ( $>0 \mathrm{~mm}$ vs. $1 \mathrm{~mm}$ vs. $2 \mathrm{~mm}$ vs. $5 \mathrm{~mm}$ ), using $1 \mathrm{~mm}$ as the referent category. Each model was refitted to test for trend across distance categories (coded as 1,2,3) by treating the categories as equally spaced on a continuous scale, after excluding the group $>0 \mathrm{~mm}$ (because the order of this group on a continuous scale cannot be definitively determined). In Model 2, margin status was fitted as three categories: positive versus close versus negative (referent category); distance was fitted as a categorical variable ( $1 \mathrm{~mm}$ (referent) vs. $2 \mathrm{~mm}$ vs. $5 \mathrm{~mm}$ ); and testing for trend across distance categories was as described for Model 1. For both adjusted models, we also examined pair-wise comparisons of the various distances used to declare a negative margin. Models were fitted using Proc NLmixed in SAS.

\section{RESULTS}

Thirty-three studies reporting on 32,363 subjects were eligible for inclusion in this review, and provided margins 
data in 28,162 subjects (1,506 LRs) included in our models. ${ }^{23-55}$ Study-specific characteristics are summarized in online-Appendix 2. Table 1 reports descriptive analyses; the median of the reported median follow-up times was 79.2 months (IQR 58.8-110.6), and the median prevalence of LR was $5.3 \%$ (IQR 2.3-7.6\%) in 28,162 subjects with margins data. In 18 studies, all subjects had stage I-II BC, and 15 studies included subjects with stage I-II BC in $>90 \%$ of the cohort-overall $>96 \%$ of subjects in this meta-analysis had stage I-II invasive BC. Studies were retrospective, with the exception of Bellon et al. ${ }^{36}$ (RCT of sequencing of therapy) and Voogd et al. ${ }^{47}$ (which scored margins for BCS arms of two RCTs). The prevalence of LR in 3,391 subjects with unknown margins (not included in models) was $10 \%$.

For analytic purposes, one study using 1 high-power field for negative margins was included in the 1-mm group, and one study using $3 \mathrm{~mm}$ was included in the $5-\mathrm{mm}$ group. ${ }^{41,47}$ Neuschatz et al. ${ }^{39}$ reported two thresholds for distance: $5 \mathrm{~mm}$ was used in our analysis to balance the distribution of studies across distance categories.

\section{Effect of Margins on LR}

Model 1 Based on 33 studies reporting LR in 1,506 of 28,162 subjects with data on positive and/or close and negative margins; study-specific and (unadjusted) pooled odds ratios (OR) are shown in Fig. 1. ${ }^{23-55}$ The proportion of subjects with LR stratified by the distance for negative margins is shown in Fig. 2. Model estimates of effect are presented in Table 2 (model 1): in the unadjusted model (which does not factor differences in follow-up time between studies) the odds of LR were associated with margin status $(P<0.001)$ and weakly associated with margin distance $(P=0.06)$ with evidence that the odds of LR decreased as the distance for declaring negative margins increased $(P=0.011$ for trend). Based on prior information and evidence of association between the odds of LR and study-specific median follow-up time $(P<0.0001)$ in this analysis, the adjusted model shows all estimates adjusted for median follow-up time (Table 2). In the adjusted model, the odds of LR were associated with margin status $(P<0.001)$ but not with margin distance $(P=0.12)$, and there was no statistical evidence that the odds of LR decreased as the distance for negative margins increased $(P=0.21$ for trend). There was no evidence of interaction: effect of margin status did not vary by distance or vice versa $(P=0.17)$.

Exclusion of two studies reporting data for locoregional recurrence from the model had little effect on model estimates. $^{30,45}$ The odds of LR were not associated with whether studies reported no losses or $<5 \%$ losses to follow-up or whether they did not provide any information on losses to follow-up $\quad(P=0.27 ; \quad$ adjusted model). ${ }^{27,31,36,38,41,48,54}$ The odds of LR did not differ according to whether or not studies included some subjects treated with quadrantectomy $(P=0.58$; adjusted model).

\section{Effect of Study Time-Frame}

Based on all 33 studies, the LR rates by median year of study recruitment declined over time (online-Fig. 3); median year of study recruitment was strongly associated with LR rates $(P<0.0001)$ in univariate analysis and also associated with LR in the adjusted model $(P=0.0086)$.

\section{Effect of Covariates in Model 1}

Only covariates meeting predefined criteria for potential association or relevance (see "Statistical Analysis" section) were further examined for effect on model estimates. Table 3 summarises results for these covariates, showing association with LR in univariate analysis, and the association once each of these covariates was entered into a model that included margins and median follow-up time; remaining associations were for age, median year of study recruitment, proportion receiving endocrine therapy, proportion ER-positive, proportion that had reexcision, and LR type.

Adjusting model 1 for covariates (Table 3) did not alter the effect of margin status: there was a significant association $(P<0.001)$ between margin status and the odds of LR in all adjusted analyses. In all (except one) of the adjusted models, there was no evidence of an association between the odds of LR and margin distance, nor evidence of a significant decrease in the odds of LR as the distance for negative margins increased (Table 3). In the model that adjusted for LR type, there was weak evidence that the odds of LR decreased as the threshold distance for negative margins increased $(P=0.074$ for trend).

\section{Pair-wise comparisons of negative distance-adjusted model 1}

The odds of LR were significantly higher for the studies using $>0 \mathrm{~mm}$ relative to $5 \mathrm{~mm}(P=0.021)$ : this finding persisted when adjusted for the covariates age $(P=0.023)$, median-year of study recruitment $(P=0.012)$, proportion with re-excision $(P=0.048)$, or LR type $(P=0.02)$. For all other pair-wise comparisons of negative distance, there were no statistically significant differences in the odds of LR in the adjusted model.

Model 2 Based on the subset of 19 studies reporting LR in 753 of 13,081 subjects with data on positive, close, and negative margins (from 14,952 subjects), estimates of effect are shown in Table 2. . $^{2,25,28,29,31,33,35-37,39-42,47-52}$ 
TABLE 1 Summary descriptive characteristics of studies in a meta-analysis of the effect of surgical margins on local recurrence in invasive breast cancer

\begin{tabular}{|c|c|c|c|}
\hline Variable & $\begin{array}{l}\text { Number of } \\
\text { studies } \\
\text { providing data }\end{array}$ & $\begin{array}{l}\text { Median } \\
\text { estimate }\end{array}$ & $\begin{array}{l}\text { Interquartile } \\
\text { range }\end{array}$ \\
\hline \multicolumn{4}{|l|}{ Study and cohort characteristics } \\
\hline \multicolumn{4}{|l|}{ Recruitment timeframe (year) } \\
\hline Start & 33 & 1984 & $1979-1990$ \\
\hline End & 33 & 1996 & $1992-2001$ \\
\hline Mid-interval & 33 & 1990 & 1985-1995 (1980-2004) \\
\hline Number of subjects in each study ${ }^{b}$ & 33 & 701 & 452-1024 (range 79-3899) \\
\hline Underlying prevalence of local recurrence & 33 & $5.3 \%$ & $2.3-7.6 \%$ \\
\hline Median (or mean) follow-up time (months) & 33 & 79.2 & $58.8-110.6$ (range $48.0-160)$ \\
\hline Median time to local recurrence (months) & 14 & 53.5 & $47.0-60.0$ \\
\hline $\begin{array}{l}\text { Proportion with systemic relapse/metastases } \\
\text { as first (or first and only) event }{ }^{\mathrm{c}}\end{array}$ & 15 & $8.3 \%$ & $5.3-12.5 \%$ \\
\hline \multicolumn{4}{|l|}{ Age, years } \\
\hline Median (or mean) & 32 & 53.4 & $51.0-57.0$ (range $45.0-60.6)$ \\
\hline Minimum value in study-specific age range & 26 & 24.0 & $22.0-25.0$ \\
\hline Maximum value in study-specific age range & 26 & 86.0 & $79.0-89.0$ \\
\hline \multicolumn{4}{|l|}{ Tumour characteristics } \\
\hline \multicolumn{4}{|l|}{ Stage distribution ${ }^{\mathrm{e}}$} \\
\hline 0 & 11 & $0 \%$ & $0-1.4 \%$ \\
\hline I & 11 & $55.0 \%$ & $52.5-56.9 \%$ \\
\hline II & 11 & $44.4 \%$ & $39.4-45.9 \%$ \\
\hline III & 11 & $0 \%$ & $0-0 \%$ (maximum $0.9 \%$ ) \\
\hline \multicolumn{4}{|l|}{ Node status } \\
\hline Positive & 30 & $25.8 \%$ & $17.9-28.8 \%$ \\
\hline Negative & 30 & $70.5 \%$ & $65.5-74.2 \%$ \\
\hline Unknown or NR & 30 & $0.9 \%$ & $0-7.7 \%$ \\
\hline Median tumour size $(\mathrm{cm})$ & 8 & 1.6 & $1.5-2.1$ \\
\hline \multicolumn{4}{|l|}{ Tumour grade distribution } \\
\hline Grade I & 15 & $25.0 \%$ & $16.7-32.1 \%$ \\
\hline Grade II & 15 & $35.5 \%$ & $31.8-41.0 \%$ \\
\hline Grade I-II combined & 17 & $66.0 \%$ & $57.5-68.9 \%$ \\
\hline Grade III & 17 & $28.3 \%$ & $20.6-30.6 \%$ \\
\hline Unknown or NR & 17 & $2.9 \%$ & $0.8-21.5 \%$ \\
\hline \multicolumn{4}{|l|}{ Estrogen receptor (ER) status } \\
\hline Positive & 24 & $45.5 \%$ & $38.4-56.3 \%$ \\
\hline Negative & 24 & $20.5 \%$ & $16.6-26.3 \%$ \\
\hline Unknown or NR & 24 & $28.4 \%$ & $14.2-42.0 \%$ \\
\hline \multicolumn{4}{|l|}{ Progesterone receptor $(\mathrm{PR})$ status } \\
\hline Positive & 10 & $40.6 \%$ & $33.5-47.0 \%$ \\
\hline Negative & 10 & $22.0 \%$ & $19.4-28.0 \%$ \\
\hline Unknown or NR & 10 & $38.4 \%$ & $23.8-44.7 \%$ \\
\hline Extensive intraductal component (EIC) (present) & 16 & $9.6 \%$ & $7.5-15.7 \%$ \\
\hline Lymphovascular invasion (LVI) (present) & 16 & $17.1 \%$ & $12.0-30.3 \%$ \\
\hline \multicolumn{4}{|l|}{ Treatment variables } \\
\hline Reexcision rate & 17 & $48.0 \%$ & $22.4-55.6 \%$ \\
\hline Received chemotherapy $^{\mathrm{d}}$ & 26 & $25.6 \%$ & $18.3-38.0 \%$ \\
\hline Received endocrine therapy & 27 & $38.0 \%$ & $19.3-59.5 \%$ \\
\hline
\end{tabular}


TABLE 1 continued

\begin{tabular}{|c|c|c|c|}
\hline Variable & $\begin{array}{l}\text { Number of } \\
\text { studies } \\
\text { providing data }\end{array}$ & $\begin{array}{l}\text { Median } \\
\text { estimate }\end{array}$ & $\begin{array}{l}\text { Interquartile } \\
\text { range }\end{array}$ \\
\hline Received any systemic therapy & 19 & $40.0 \%$ & $24.0-77.0 \%$ \\
\hline \multicolumn{4}{|l|}{ Radiation therapy (doses in Gy) } \\
\hline \multicolumn{4}{|l|}{ Whole breast radiotherapy $(\mathrm{WBR})^{\mathrm{f}}$} \\
\hline Median (or mean) WBR dose & 26 & $47.2 \mathrm{~Gy}$ & $45.0-50.0 \mathrm{~Gy}$ \\
\hline Minimum dose in study-specific WBR range & 17 & 44.0 Gy & $40.0-46.0 \mathrm{~Gy}$ \\
\hline Maximum dose in study-specific WBR range & 17 & 50.4 Gy & $50.0-54.0 \mathrm{~Gy}$ \\
\hline \multicolumn{4}{|l|}{ Radiotherapy boost } \\
\hline Received boost & 30 & $96.0 \%$ & $73.1-100 \%$ \\
\hline Median boost dose & 12 & 10.0 Gy & 10.0-13.1 Gy \\
\hline Minimum dose in study-specific boost range & 19 & $10.0 \mathrm{~Gy}$ & $9.0-14.8$ Gy \\
\hline Maximum dose in study-specific boost range & 19 & $18.0 \mathrm{~Gy}$ & 16.0-20.0 Gy \\
\hline \multicolumn{4}{|l|}{ Total dose to tumour bed (TDT) } \\
\hline Median TDT & 13 & $61.0 \mathrm{~Gy}$ & $60.0-62.0 \mathrm{~Gy}$ \\
\hline Received radiation to regional nodes ${ }^{\mathrm{g}}$ & 11 & $10.5 \%$ & $4.3-26.0 \%$ \\
\hline
\end{tabular}

${ }^{a}$ Variables reported in fewer than half of the included studies were not considered in our models

b Three studies reported data per affected/treated breast resulting in 42 additional breasts included as subjects in the total 32,363 subjects

${ }^{c}$ Reported in 17 studies; however, we excluded 2 studies ${ }^{30,49}$ (reporting systemic relapse combined with other cancers and/or contralateral breast cancer) from descriptive analysis of this variable

d Type of chemotherapy varied across studies as well as within individual studies, or was not specified in some studies (details available from authors)

e Stage distribution (where specified) - 18 studies included only subjects with stage I-II invasive breast cancer (only some of these studies reported exact distribution) and 15 studies included stage I-II in the vast majority of subjects (see "Methods" section); overall >96 \% of subjects had stage I-II invasive breast cancer

${ }^{\mathrm{f}}$ Whole breast radiotherapy (WBR) is an inclusion criterion in this review (all subjects had WBR)

g Use of nodal irradiation was reported in 16 studies, however specific data were provided in 11 studies

In the unadjusted model, the odds of LR were significantly associated with margin status $(P<0.001)$ but not with negative distance $(P=0.32)$; however, there was weak evidence that LR odds decreased as the distance for negative margins increased $(P=0.074$ for trend). In the adjusted model 2, the odds of LR were associated with margin status $(P<0.001)$ but not with margin distance $(P=0.9)$ and there was no statistical evidence that the odds of LR decreased as the distance for declaring negative margins increased $(P=0.58$ for trend). There was no evidence of interaction between margin status and distance $(P=0.53)$.

\section{Effect of Covariates in model 2}

Table 4 shows the covariates associated with LR $(P<0.1)$ in a univariate analysis, and associations after entering each covariate into a model that also included margins and follow-up time. Adjusting model 2 for each covariate did not alter the effect of margin status; there was significant association $(P<0.001)$ between margin status and the odds of LR in all adjusted models (Table 4). In all adjusted models, there was no evidence of association between margin distance and the odds of LR ( $P$ value range 0.32-0.95) nor evidence that the odds of LR decreased as the threshold distance for negative margins increased ( $P$ for trend range 0.14-0.75).

\section{Pair-Wise Comparisons of Negative Distance- Adjusted Model 2}

For all pairwise comparisons of negative distance (1 vs. $2 \mathrm{~mm}, 1$ vs. $5 \mathrm{~mm}$, or 2 vs. $5 \mathrm{~mm}$ ), there were no significant differences in the odds of LR in the adjusted model. There was no evidence of an association between the stagegroup categories (defined in Methods, "Covariates" section) and LR in the margins-adjusted models $(P=0.25$, $P=0.65$ for models 1 and 2 respectively).

\section{DISCUSSION}

It is remarkable that more than 25 years after the demonstration that survival after BCS and whole breast irradiation is equivalent to survival after mastectomy, there 


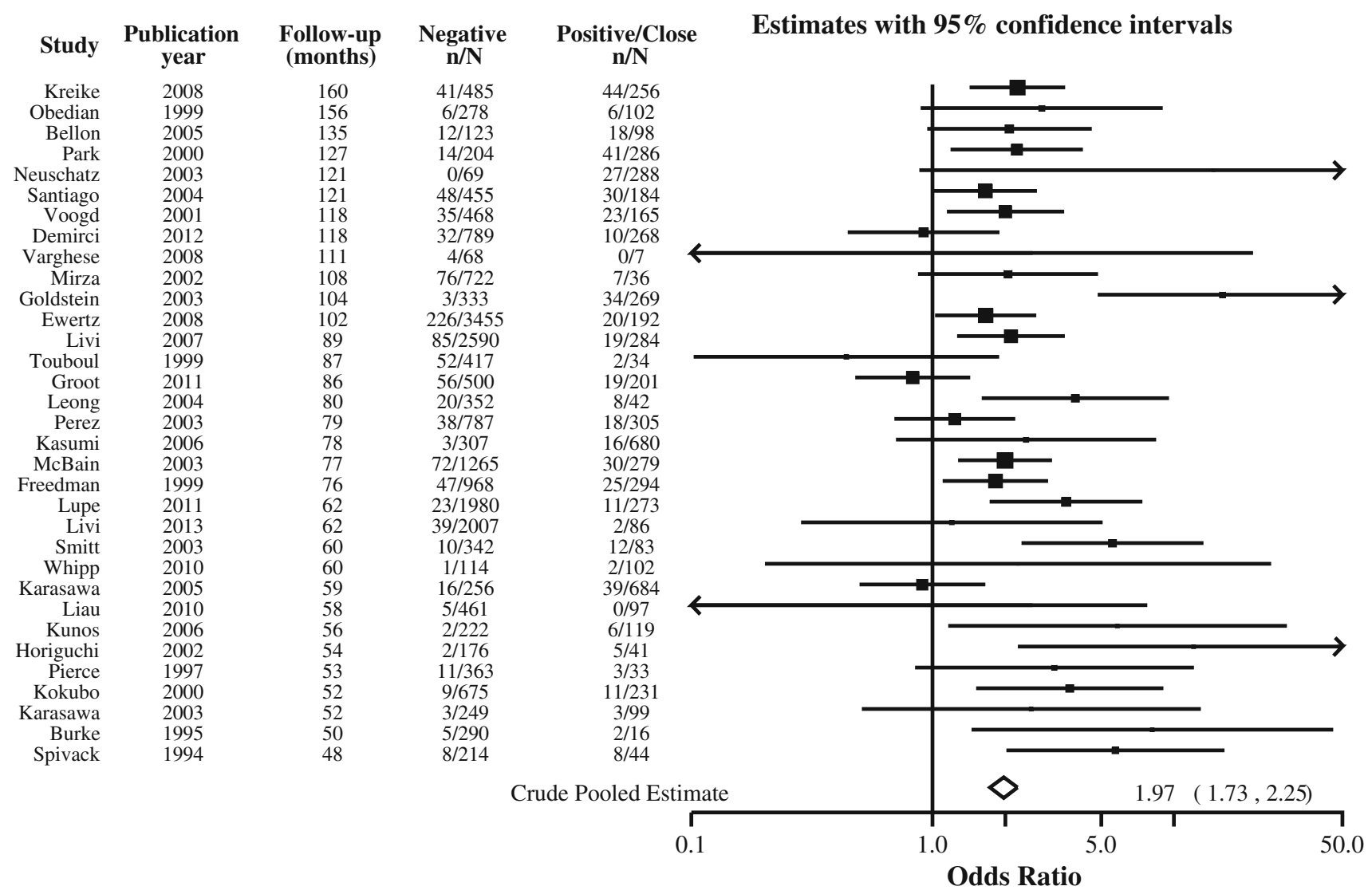

FIG. 1 The effect of margin status (positive/close relative to negative) on local recurrence: study-specific OR, ordered by median follow-up time. A crude pooled odds ratio of 1.97 (CI 1.73-2.25) is shown [modeled pooled odds ratio, adjusted for negative distance was

is still no consensus on what constitutes an adequate negative margin for BCT. ${ }^{1,2}$ Ink on tumour cells, a universally accepted definition of a positive margin, is associated with an increased risk of LR, but the amount of normal breast tissue which constitutes the optimal negative margin remains controversial. We therefore have systematically examined the evidence on the association of surgical margins with LR in early-stage invasive BC, providing estimates of effect that factor both margin status and the threshold distance for declaring negative margins across studies. We confirm that positive and close margins (combined) significantly increase the odds of LR (OR 1.96; $P<0.001)$ relative to negative margins. However, the distance used to declare negative margins across studies was either weakly associated or not associated with the odds of LR in our two models respectively, and once adjusted for study-specific median follow-up time there was no statistical evidence that the distance used to define a negative margin significantly contributed to the risk of LR ( $P=0.12$ and $P=0.9$ in models 1 and 2 ). In addition, in the adjusted models, there was no evidence that the odds of
1.98 (CI 1.73-2.25) and also adjusted for median follow-up time was 1.96 (CI 1.72-2.24)]. Data for $\mathrm{Mirza}^{45}$ and Ewertz ${ }^{30}$ are for locoregional recurrence

LR significantly decreased as the distance for defining negative margins increased $(P=0.21$ and $P=0.58$ for trend in models 1 and 2 respectively).

A survey of surgeons selected from a population-based sample, who were asked what negative margin width precluded the need for reexcision, and offered the choices of tumour not touching ink, $>1-2,>5$, and $>10 \mathrm{~mm}$, found that no choice was endorsed by more than $50 \%$ of the respondents, and only $11 \%$ selected tumour not touching ink. ${ }^{90}$ Similar findings were reported by Taghian et al. ${ }^{15}$ in a survey of 1,133 radiation oncologists in North America and Europe. Again, no margin width was endorsed by more than $50 \%$ with European radiation oncologists tending to favor larger margins than their North American counterparts. The net result of this confusion is wide variation in the use of reexcision with reported rates ranging from 6 to $49 \%$ of cases, with the majority noting re-excision in 15$30 \%$ of patients. ${ }^{18,20,91-93}$ McCahill et al. ${ }^{18}$ reported that of 2,200 BCS patients, 509 had reexcision, and $48 \%$ of these reexcisions were performed in patients with negative margins to obtain a more widely clear margin. Thus, failure 


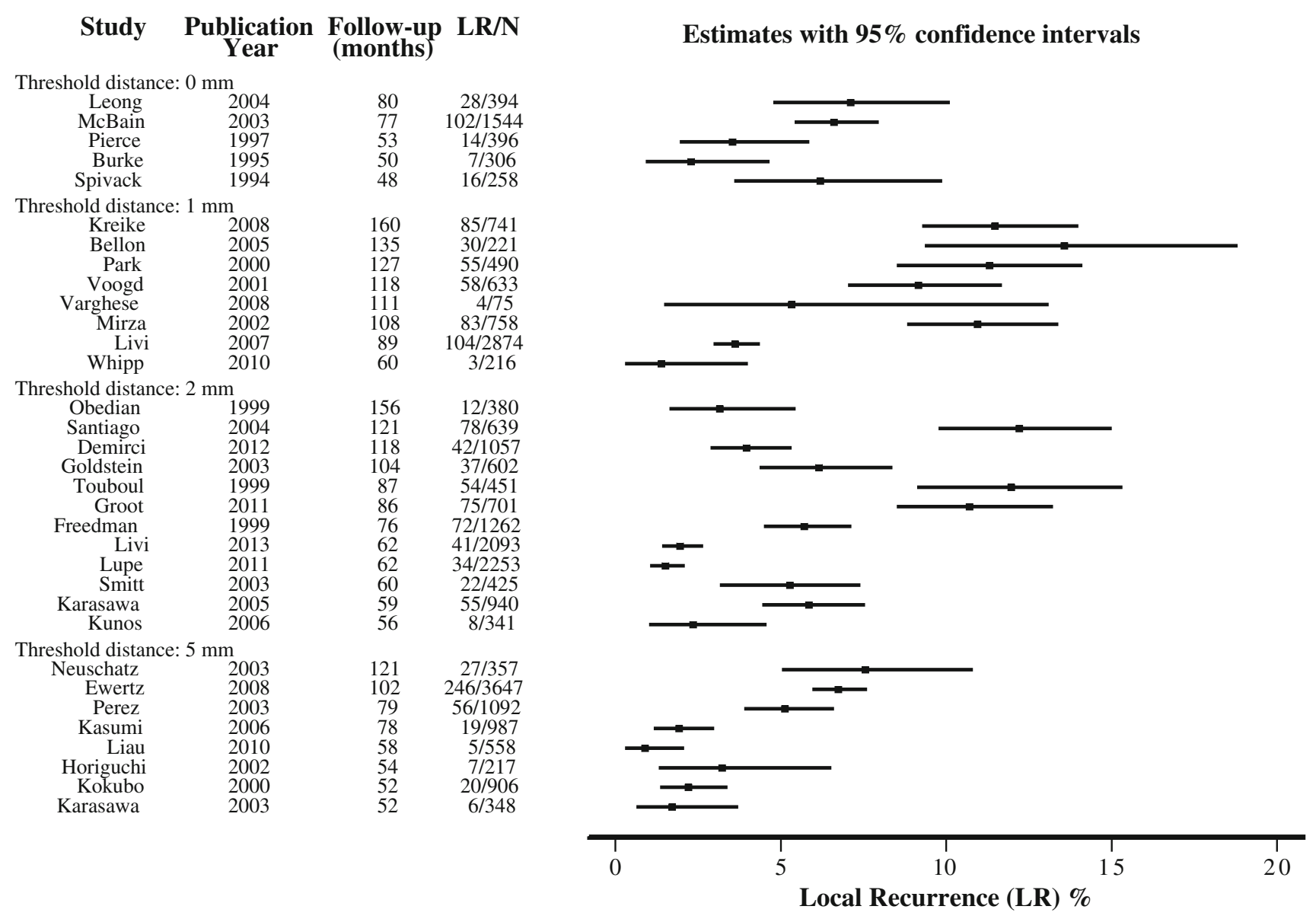

FIG. 2 Study-specific proportion with LR stratified by threshold distance for negative margins, ordered by median follow-up time. Data for Neuschatz ${ }^{39}$ were based on 5-mm distance; data for Perez ${ }^{41}$

to achieve consensus on margin width is a potential cause of unnecessary surgery, leading to worse cosmetic outcome, and increased health care costs. The findings of our analysis should therefore guide evidence-based practice through highlighting that more widely clear margins are unlikely to confer patient benefit.

Examination of covariates in our meta-analysis showed that the association between margin status and the odds of LR was significant in all adjusted models. The microscopic status of surgical margins, although not an exact test, because it relies on sampling of representative tissue sections, is a robust prognostic factor for LR. In contrast, the distance used to define negative margins was not significantly associated with LR even after adjustment for potential confounders. We found little to no evidence of association between margin distance and the odds of LR, and there was little to no evidence that the odds of LR decreased as the distance for declaring negative margins across studies increased (Tables 3, 4). It may be noted that were based on 3-mm distance (this was included in the 5-mm group in our analysis); data for Mirza ${ }^{45}$ and Ewertz ${ }^{30}$ were for locoregional recurrence

the OR for the studies with the widest threshold distance $(5 \mathrm{~mm})$ to define negative margins have relatively lower point estimates than the other categories; however, aside from the lack of statistical association, the estimates should be interpreted with consideration of the effect of adjustment for important covariates. For example, in Table 4, it is clear that adjustment for receipt of endocrine therapy or a radiation boost almost nullify differences in the estimated ORs for wide $(5 \mathrm{~mm})$ relative to narrow $(1 \mathrm{~mm})$ negative margins.

Pairwise comparison between distance categories for negative margins (in the adjusted models) showed that there were no significant differences in the odds of LR, except that the odds of LR were higher for studies using $>0 \mathrm{~mm}$ relative to $5 \mathrm{~mm}(P=0.021)$ in the adjusted model 1. For all other pairwise comparisons of negative distance, there were no statistically significant differences in the odds of LR in either of the adjusted models. The number of studies reporting negative margins as $>0 \mathrm{~mm}$ 
TABLE 2 Models of the effect of surgical margins on LR in early-stage invasive breast cancer

\begin{tabular}{|c|c|c|c|c|c|}
\hline & \multicolumn{2}{|c|}{ Number in model } & \multicolumn{3}{|c|}{ Model estimates adjusted for study-specific median follow-up time } \\
\hline & Subjects & LR & $\begin{array}{l}\text { Odds of } \\
\text { LR } \\
\text { (odds ratio) }\end{array}$ & $95 \% \mathrm{CI}$ & $\begin{array}{l}P \text { value }^{\mathrm{a}} \\
{[P \text { for trend }]}\end{array}$ \\
\hline $\begin{array}{l}\text { Model } 1 \text { (median study-specific median } \\
\text { follow-up time } 6.6 \text { years) }\end{array}$ & 28,162 & 1,506 & - & - & \\
\hline Margin status & & & & & $<0.001$ \\
\hline Negative & 21,984 & 1,005 & 1.0 & - & \\
\hline Positive/close & 6,178 & 501 & 1.96 & $1.72-2.24$ & \\
\hline Threshold distance for negative margins ${ }^{\mathrm{b}}$ & & & & & $0.12\left[0.21^{\mathrm{c}}\right]$ \\
\hline$>0 \mathrm{~mm}$ & 2,898 & 167 & 1.47 & $0.67-3.20$ & \\
\hline $1 \mathrm{~mm}$ & 6,008 & 422 & 1.0 & - & \\
\hline $2 \mathrm{~mm}$ & 11,144 & 530 & 0.95 & $0.54-1.67$ & \\
\hline $5 \mathrm{~mm}$ & 8,112 & 386 & 0.65 & $0.34-1.26$ & \\
\hline $\begin{array}{l}\text { Model } 2 \text { (median study-specific median } \\
\text { follow-up time } 8.7 \text { years) }\end{array}$ & 13,081 & 753 & - & - & - \\
\hline Margin status & & & & & $<0.001$ \\
\hline Negative & 9,033 & 393 & 1.0 & - & \\
\hline Close & 2,407 & 176 & 1.74 & $1.42-2.15$ & \\
\hline Positive & 1,641 & 184 & 2.44 & $1.97-3.03$ & \\
\hline Threshold distance for negative margins ${ }^{b}$ & & & & & $0.90[0.58]$ \\
\hline $1 \mathrm{~mm}$ & 2,376 & 235 & 1.0 & - & \\
\hline $2 \mathrm{~mm}$ & 8,350 & 414 & 0.91 & $0.46-1.80$ & \\
\hline $5 \mathrm{~mm}$ & 2,355 & 103 & 0.77 & $0.32-1.87$ & \\
\hline
\end{tabular}

${ }^{\text {a }} P$ reports $P$ value for association; $P$ in square brackets gives $P$ for trend and reflects whether there was statistical evidence of a decrease in the odds of LR as the threshold distance for declaring negative margins increased

b Threshold distance for negative margins based on $>0 \mathrm{~mm}$ (5 studies), $1 \mathrm{~mm}$ (referent; 8 studies), $2 \mathrm{~mm}$ (12 studies), and $5 \mathrm{~mm}$ ( 8 studies) in model 1; and based on $1 \mathrm{~mm}$ (referent; 6 studies), $2 \mathrm{~mm}$ (10 studies), and $5 \mathrm{~mm}$ (3 studies) in model 2

c Trend tested excluding studies using $>0 \mathrm{~mm}$ (test based on 28 studies) for model 1 - see "Methods" section

was small, and given the lack of significant differences among the other pairwise comparisons of margin distance and the lack of overall significance of increasing margin width in decreasing LR in the models, this is unlikely to be clinically significant.

Relative to our previous meta-analysis on margins in BCT, the updated OR estimates for the effect of margin status have remained largely unchanged, except for improved precision from the larger dataset in the present analysis. ${ }^{10}$ We previously reported weak evidence of a trend showing that the odds of LR decreased as the threshold distance for declaring negative margins increased; however, this trend was not significant after adjustment for covariates. ${ }^{10}$ In the present meta-analysis that included several relatively more recent publications, there was even less evidence of an effect of negative distance (relative to our prior analysis), and after adjustment for study-specific median follow-up time, there was no evidence that the distance used to define negative margins significantly contributed to the odds of LR. Overall, data synthesis in 28,162 subjects indicates that the risk of LR is not driven by the distance defining negative margins.

It is noteworthy that the overall median prevalence of LR in our analysis was only $5.3 \%$, despite the fact that many of the included studies antedated the routine use of systemic therapy for small, node-negative BCs. The observed temporal decline in LR can likely be attributed to the increasing use of systemic therapy, particularly in studies after 1990. Our work does not capture the full effect of improvements in systemic therapy, such as the use of aromatase inhibitors or HER2-directed therapy, such as trastuzumab, on local control, because the cohorts in this meta-analysis generally predated the routine use of these agents as adjuvant therapy (and given that our analysis required a minimum study median follow-up of 4 years to ensure a sufficient number of events). However, it is increasingly evident that therapies that improve distant disease-free survival result in a parallel decrease in LR, a concept most clearly illustrated by the decrease in LR observed in patients with HER2-overexpressing cancers 
TABLE 3 Model 1-estimating the effect of surgical margins on LR in invasive breast cancer adjusted for covariates (covariates examined in model 1 were selected using criteria described in "Statistical Analysis" section)

\begin{tabular}{|c|c|c|c|c|c|c|c|c|c|c|}
\hline \multirow{2}{*}{$\begin{array}{l}\text { Covariate (covariate } \\
\text { definition and categories } \\
\text { described in "Methods" } \\
\text { section) }\end{array}$} & \multirow[b]{2}{*}{$\begin{array}{l}\text { No. of } \\
\text { studies }\end{array}$} & \multicolumn{2}{|c|}{$\begin{array}{l}P \text { for association of } \\
\text { covariate with LR }\end{array}$} & \multicolumn{2}{|c|}{$\begin{array}{l}\text { Margin status } \\
\text { (adjusted OR) }\end{array}$} & \multicolumn{4}{|c|}{$\begin{array}{l}\text { Threshold distance for } \\
\text { negative margins (adjusted } \\
\text { OR) }\end{array}$} & \multirow{2}{*}{$\begin{array}{l}P \text { for association } \\
{[P \text { for trend }] \text { for }} \\
\text { margin distance } \\
\text { Adjusted } \\
\text { for } \\
\text { covariate }\end{array}$} \\
\hline & & Unadjusted & $\begin{array}{l}\text { Adjusted } \\
\text { for margins \& } \\
\text { follow-up } \\
\text { time }\end{array}$ & Negative & $\begin{array}{l}\text { Positive/ } \\
\text { close }\end{array}$ & $>0 \mathrm{~mm}$ & $1 \mathrm{~mm}$ & $2 \mathrm{~mm}$ & $5 \mathrm{~mm}$ & \\
\hline $\begin{array}{l}\text { Effect of margins } \\
\quad \text { (adjusted for follow-up time) }\end{array}$ & 33 & & & 1.0 & $1.96 * *$ & 1.47 & 1.0 & 0.95 & 0.65 & $0.12[0.21]$ \\
\hline Age & 32 & 0.11 & 0.089 & 1.0 & $1.91 * *$ & 1.56 & 1.0 & 1.13 & 0.72 & $0.12[0.29]$ \\
\hline $\begin{array}{l}\text { Median-year of study } \\
\text { recruitment }\end{array}$ & 33 & $<0.0001$ & 0.0086 & 1.0 & $1.96 * *$ & 1.47 & 1.0 & 0.95 & 0.65 & $0.26[0.14]$ \\
\hline Proportion had endocrine therapy & 27 & $<0.0001$ & 0.0011 & 1.0 & $2.07 * *$ & 1.11 & 1.0 & 0.91 & 0.77 & $0.19[0.32]$ \\
\hline Proportion ER-positive & 24 & 0.012 & 0.023 & 1.0 & $2.26 * *$ & 0.87 & 1.0 & 0.98 & 0.56 & $0.44[0.25]$ \\
\hline Proportion had reexcision $^{\mathrm{a}}$ & 17 & 0.032 & 0.088 & 1.0 & $2.06 * *$ & 1.41 & 1.0 & 0.82 & 0.52 & $0.22[0.13]$ \\
\hline LR type (first vs. any) ${ }^{\mathrm{b}}$ & 33 & 0.12 & 0.058 & 1.0 & $1.96 * *$ & 1.11 & 1.0 & 0.83 & 0.51 & $0.063[0.074]$ \\
\hline
\end{tabular}

** Indicates OR significantly different to referent at $P<0.001$

${ }^{\text {a }}$ Odds of LR increased as proportion receiving reexcision increased

b LR type (see "Definition of Variables" section in Methods): odds of LR were lower for 'first' than 'any'

TABLE 4 Model 2-estimating the effect of surgical margins on LR in invasive breast cancer adjusted for covariates (covariates examined in model 2 were selected using criteria described in "Statistical Analysis" section)

\begin{tabular}{|c|c|c|c|c|c|c|c|c|c|c|}
\hline \multirow{2}{*}{$\begin{array}{l}\text { Covariate (covariate } \\
\text { definition and categories } \\
\text { described in "Methods" } \\
\text { section) }\end{array}$} & \multirow[b]{2}{*}{$\begin{array}{l}\text { No. of } \\
\text { studies }\end{array}$} & \multicolumn{2}{|c|}{$\begin{array}{l}P \text { for association of covariate } \\
\text { with LR }\end{array}$} & \multicolumn{3}{|c|}{$\begin{array}{l}\text { Margin status (adjusted } \\
\text { OR) }\end{array}$} & \multicolumn{3}{|c|}{$\begin{array}{l}\text { Threshold distance } \\
\text { for negative margins } \\
\text { (adjusted OR) }\end{array}$} & \multirow{2}{*}{$\begin{array}{l}P \text { for } \\
\text { association } \\
{[P \text { for trend }] \text { for }} \\
\text { margin distance } \\
\text { Adjusted } \\
\text { for } \\
\text { covariate }\end{array}$} \\
\hline & & Unadjusted & $\begin{array}{l}\text { Adjusted } \\
\text { for margins } \\
\text { and follow-up } \\
\text { time }\end{array}$ & Negative & Close & Positive & $1 \mathrm{~mm}$ & $2 \mathrm{~mm}$ & $5 \mathrm{~mm}$ & \\
\hline $\begin{array}{l}\text { Effect of margins } \\
\quad \text { (adjusted for follow-up time) }\end{array}$ & 19 & - & - & 1.0 & $1.74 * *$ & $2.44 * *$ & 1.0 & 0.91 & 0.77 & $0.53[0.58]$ \\
\hline Age & 18 & 0.089 & 0.11 & 1.0 & $1.68^{* *}$ & $2.35 * *$ & 1.0 & 1.12 & 0.94 & $0.86[0.58]$ \\
\hline $\begin{array}{l}\text { Median-year of study } \\
\text { recruitment }\end{array}$ & 19 & 0.0013 & 0.0055 & 1.0 & $1.76^{* *}$ & $2.45 * *$ & 1.0 & 0.83 & 0.57 & $0.32[0.14]$ \\
\hline $\begin{array}{l}\text { Proportion had endocrine } \\
\text { therapy }\end{array}$ & 16 & 0.0003 & 0.012 & 1.0 & $1.77 * *$ & $2.53 * *$ & 1.0 & 0.98 & 0.90 & $0.95[0.75]$ \\
\hline Proportion had radiation boost & 18 & 0.015 & 0.34 & 1.0 & $1.75^{* *}$ & $2.45 * *$ & 1.0 & 0.82 & 0.92 & $0.86[0.75]$ \\
\hline Proportion ER-positive & 15 & 0.036 & 0.078 & 1.0 & $1.92 * *$ & $2.66 * *$ & 1.0 & 1.08 & 0.63 & $0.67[0.34]$ \\
\hline Proportion had re-excision $^{\mathrm{a}}$ & 11 & 0.0017 & 0.0029 & 1.0 & $1.97 * *$ & $2.84 * *$ & 1.0 & 0.85 & 0.69 & $0.64[0.34]$ \\
\hline LR type (first vs. any) & 19 & 0.46 & 0.19 & 1.0 & $1.74 * *$ & $2.44 * *$ & 1.0 & 0.85 & 0.65 & $0.67[0.34]$ \\
\hline
\end{tabular}

** Indicates OR significantly different to referent at $P<0.001$

a Odds of LR increased as proportion receiving reexcision increased

with the use of adjuvant trastuzumab. ${ }^{94-96}$ The failure of more widely clear margins to decrease LR significantly in the setting of relatively less use or less effective adjuvant therapy than is in use today makes it exceedingly unlikely that the inclusion of even more recently treated cohorts of $\mathrm{BC}$ patients would change our results, but if it did this would be expected to lead to even less effect from wider margins. Although the underlying (crude) LR rates for studies included in this review have indeed declined with time, adjusting for this covariate did not alter the estimated ORs for margin status, which remained strongly associated with odds of LR. Therefore, we conclude that the 
prognostic value of the status of surgical margins (positive vs. negative) in BCT is not diminished by temporal declines in LR rates, and obtaining negative margins remains relevant to current oncologic practice.

This work focuses on the relative effect of surgical margins; the absence of a significant effect in our models for some variables may be due (at least in part) to the use of study-level information, or the infrequent reporting of data for some variables, such as LVI or EIC. These limitations are inherent in study-level meta-analysis and could be overcome by using individual patient data. Furthermore, the relatively homogeneous distribution of some covariates across studies (such as median age, aggregate dose of WBR) also accounts for a lack of association (or of strong association) for some factors. This does not mean that these factors are unrelated to LR risk; it means that these variables (at an aggregate level) were similar across studies and did not account for differences in the odds of LR in modeling the effect of margins. Additionally, it is increasingly clear that the risk of LR varies with the molecular subtype of $\mathrm{BC}$ as approximated by ER, PR, and HER2 status. ${ }^{97,98}$ We were unable to evaluate the interaction between BC subtype and margin width due to the lack of information on subtype or on HER2 status in a majority of studies. However, the finding that differences in rates of LR by subtype are similar after both BCT and mastectomy suggests that larger surgical excisions, whether in the form of more widely clear margins or mastectomy, are unlikely to alter aggressive biology. ${ }^{99}$ Negative surgical margins do not guarantee the absence of residual cancer within the breast; histological studies using serial sub-gross sectioning of the breast have shown that additional cancer can be found in the breast in a substantial proportion of women despite adequate surgical resection. ${ }^{100,101}$ A negative margin predicts that residual tumour burden is minimal and is likely to be controlled with adjuvant therapies.

This meta-analysis has investigated the association between surgical margins and LR, including the various distances used to define negative margins across a large number of studies. The implications for practice are that the association between margins and the risk of LR is largely driven by margin status, and ensuring negative margins in BCT contributes to reducing the risk of LR; however, the threshold distance for defining negative margins does not significantly contribute to the odds of LR. The adoption of wider margins for declaring negative margins in BCT is unlikely to have a substantial additional benefit for long-term local control over a minimally defined negative margin width in patients undergoing BCT for invasive $\mathrm{BC}$.

ACKNOWLEDGMENT This work was partly funded by National Health and Medical Research Council (NHMRC) program grant
633003 to the Screening \& Test Evaluation Program. Assoc/Prof Houssami receives research support through a National Breast Cancer Foundation (NBCF Australia) Practitioner Fellowship.

\section{REFERENCES}

1. Veronesi U, Cascinelli N, Mariani L, et al. Twenty-year followup of a randomized study comparing breast-conserving surgery with radical mastectomy for early breast cancer. $N$ Engl $J$ Med. 2002;347:1227-32.

2. Fisher B, Anderson S, Bryant J, et al. Twenty-year follow-up of a randomized trial comparing total mastectomy, lumpectomy, and lumpectomy plus irradiation for the treatment of invasive breast cancer. N Engl J Med. 2002;347:1233-41.

3. Van Dongen JA, Voogd AC, Fentiman IS, et al. Long-term results of a randomized trial comparing breast-conserving therapy with mastectomy: European Organization for Research and Treatment of Cancer 10801 trial. J Natl Cancer Inst. 2000;92:1143-50.

4. Poggi MM, Danforth DN, Sciuto LC, et al. Eighteen-year results in the treatment of early breast carcinoma with mastectomy versus breast conservation therapy: the National Cancer Institute Randomized Trial. Cancer. 2003;98:697-702.

5. Blichert-Toft M, Rose C, Andersen JA, et al. Danish randomized trial comparing breast conservation therapy with mastectomy: six years of life-table analysis. Danish Breast Cancer Cooperative Group. J Natl Cancer Inst Monogr. 1992;(11):19-25.

6. Clarke M, Collins R, Darby S, et al. Effects of radiotherapy and of differences in the extent of surgery for early breast cancer on local recurrence and 15-year survival: an overview of the randomised trials. Lancet. 2005;366:2087-106.

7. Newman LA, Kuerer HM. Advances in breast conservation therapy. J Clin Oncol. 2005;23:1685-97.

8. Morrow M, Strom EA, Bassett LW et al. Standard for breast conservation therapy in the management of invasive breast carcinoma. CA Cancer J Clin. 2002;52:277-300.

9. Singletary SE. Surgical margins in patients with early-stage breast cancer treated with breast conservation therapy. Am J Surg. 2002;184:383-93.

10. Houssami N, Macaskill P, Marinovich ML, et al. Meta-analysis of the impact of surgical margins on local recurrence in women with early-stage invasive breast cancer treated with breast-conserving therapy. Eur J Cancer. 2010;46:3219-32.

11. Carlson RW, Allred DC, Anderson BO, et al. Breast cancer. Clinical practice guidelines in oncology. J Natl Compr Cancer Netw. 2009;7:122-92.

12. Schwartz GF, Veronesi U, Clough KB, et al. Consensus conference on breast conservation. J Am Coll Surg. 2006;203:198207.

13. Singletary SE. Surgical margins in patients with early-stage breast cancer treated with breast conservation therapy. Am J Surg. 2002;184:383-93.

14. Morrow M. Margins in breast-conserving therapy: have we lost sight of the big picture? Expert Rev Anticancer Ther. 2008;8:1193-6.

15. Taghian A, Mohiuddin M, Jagsi R, Goldberg S, Ceilley E, Powell S. Current perceptions regarding surgical margin status after breast-conserving therapy: results of a survey. Ann Surg. 2005;241:629-39.

16. Luini A, Rososchansky J, Gatti G, et al. The surgical margin status after breast-conserving surgery: discussion of an open issue. Breast Cancer Res Treat. 2009;113:397-402.

17. MacDonald S, Taghian AG. Prognostic factors for local control after breast conservation: does margin status still matter? J Clin Oncol. 2009;27:4929-30. 
18. McCahill LE, Single RM, Aiello Bowles EJ, et al. Variability in reexcision following breast conservation surgery. $\mathrm{J} \mathrm{Am} \mathrm{Med}$ Assoc. 2012;307:467-75.

19. Sakamoto G, Inaji H, Akiyama F, et al. General rules for clinical and pathological recording of breast cancer 2005. Breast Cancer. 2005;12 Suppl:27.

20. Morrow M, Jagsi R, Alderman AK, et al. Surgeon recommendations and receipt of mastectomy for treatment of breast cancer. J Am Med Assoc. 2009;302:1551-6.

21. Altman DG. Systematic reviews of evaluations of prognostic variables. In: Egger M, Smith GD, Altman DG, eds. Systematic reviews in health care: meta-analysis in context, 2nd edn. London: BMJ Publishing Group; 2001:228-47.

22. Randolph A, Bucher H, Richardson WS, et al. Prognosis. In: Guyatt G, Rennie D, eds. Users' guide to the medical literature. A manual for evidence-based clinical practice. Chicago: AMA Press; 2002; 141-54.

23. Livi L, Meattini I, Franceschini D, et al. Radiotherapy boost dose-escalation for invasive breast cancer after breast-conserving surgery: 2093 patients treated with a prospective margindirected policy. Radiother Oncol. 2013;108:273-8.

24. Demirci S, Broadwater G, Marks LB, Clough R, Prosnitz LR. Breast conservation therapy: the influence of molecular subtype and margins. Int J Radiat Oncol Biol Phys. 2012;83:814-20.

25. Lupe K, Truong PT, Alexander C, Lesperance M, Speers C, Tyldesley S. Subsets of women with close or positive margins after breast-conserving surgery with high local recurrence risk despite breast plus boost radiotherapy. Int J Radiat Oncol Biol Phys. 2011;81:e561-8.

26. Groot G, Rees H, Pahwa P, Kanagaratnam S, Kinloch M. Predicting local recurrence following breast-conserving therapy for early stage breast cancer: the significance of a narrow $(\leq 2 \mathrm{~mm})$ surgical resection margin. J Surg Oncol. 2011;103:212-6.

27. Liau SS, Cariati M, Noble D, Wilson C, Wishart GC. Audit of local recurrence following breast conservation surgery with 5$\mathrm{mm}$ target margin and hypofractionated 40-Gray breast radiotherapy for invasive breast cancer. Ann Royal Coll Surg Engl. 2010;92:562-8.

28. Whipp E, Beresford M, Sawyer E, Halliwell M. True local recurrence rate in the conserved breast after magnetic resonance imaging-targeted radiotherapy. Int J Radiat Oncol Biol Phys. 2010;76:984-90.

29. Kreike B, Hart AAM, van de Velde T, et al. Continuing risk of ipsilateral breast relapse after breast-conserving therapy at longterm follow-up. Int J Radiat Oncol Biol Phys. 2008;71:1014-21.

30. Ewertz M, Moe Kempel M, During M, et al. Breast conserving treatment in Denmark, 1989-1998. A nationwide populationbased study of the Danish Breast Cancer Co-operative Group. Acta Oncol. 2008;47:682-90.

31. Varghese P, Gattuso JM, Mostafa AIH, et al. The role of radiotherapy in treating small early invasive breast cancer. Eur J Surg Oncol. 2008;34:369-76.

32. Livi L, Paiar F, Saieva C, et al. Survival and breast relapse in 3834 patients with T1-T2 breast cancer after conserving surgery and adjuvant treatment. Radiother Oncol. 2007;82:287-93.

33. Kunos C, Latson L, Overmoyer B, et al. Breast conservation surgery achieving $>$ or $=2 \mathrm{~mm}$ tumor-free margins results in decreased local-regional recurrence rates. Breast J. 2006;12:2836.

34. Kasumi F, Takahashi K, Nishimura S, et al. CIH-Tokyo experience with breast-conserving surgery without radiotherapy: 6.5 year follow-up results of 1462 patients. Breast J. 2006;12:Suppl-90.

35. Karasawa K, Mitsumori M, Yamauchi C, et al. Treatment outcome of breast-conserving therapy in patients with positive or close resection margins: Japanese multi-institute survey for radiation dose effect. Breast Cancer. 2005;12:91-8.

36. Bellon JR, Come SE, Gelman RS, et al. Sequencing of chemotherapy and radiation therapy in early-stage breast cancer: updated results of a prospective randomized trial. J Clin Oncol. 2005;23:1934-40.

37. Santiago RJ, Wu L, Harris E, et al. Fifteen-year results of breastconserving surgery and definitive irradiation for stage I and II breast carcinoma: The University of Pennsylvania experience. Int J Radiat Oncol Biol Phys. 2004;58:233-40.

38. Leong C, Boyages J, Jayasinghe UW, et al. Effect of margins on ipsilateral breast tumor recurrence after breast conservation therapy for lymph node-negative breast carcinoma. Cancer. 2004;100:1823-32.

39. Neuschatz AC, DiPetrillo T, Safaii H, Price LL, Schmidt-Ullrich RK, Wazer DE. Long-term follow-up of a prospective policy of margin-directed radiation dose escalation in breast-conserving therapy. Cancer. 2003;97:30-9.

40. Goldstein NS, Kestin L, Vicini F. Factors associated with ipsilateral breast failure and distant metastases in patients with invasive breast carcinoma treated with breast-conserving therapy: a clinicopathologic study of 607 neoplasms from 583 patients. Am J Clin Pathol. 2003;120:500-27.

41. Perez CA. Conservation therapy in T1-T2 breast cancer: past, current issues, and future challenges and opportunities. Cancer J. 2003;9:442-53.

42. Smitt MC, Nowels K, Carlson RW, Jeffrey SS. Predictors of reexcision findings and recurrence after breast conservation. Int J Radiat Oncol Biol Phys. 2003;57:979-85.

43. Karasawa K, Obara T, Shimizu T, et al. Outcome of breastconserving therapy in the Tokyo Women's Medical University Breast Cancer Society experience. Breast Cancer. 2003;10:2418.

44. McBain CA, Young EA, Swindell R, Magee B, Stewart AL. Local recurrence of breast cancer following surgery and radiotherapy: incidence and outcome. Clin Oncol ( $R$ Coll Radiol). 2003;15:25-31.

45. Mirza NQ, Vlastos G, Meric F, et al. Predictors of locoregional recurrence among patients with early-stage breast cancer treated with breast-conserving therapy. Ann Surg Oncol. 2002;9:25665.

46. Horiguchi J, Koibuchi Y, Takei H, et al. Breast-conserving surgery following radiation therapy of $50 \mathrm{~Gy}$ in stages I and II carcinoma of the breast: the experience at one institute in Japan. Oncol Rep. 2002;9:1053-7.

47. Voogd AC, Nielsen M, Peterse JL, et al. Differences in risk factors for local and distant recurrence after breast-conserving therapy or mastectomy for stage I and II breast cancer: pooled results of two large European randomized trials. J Clin Oncol. 2001;19:1688-97.

48. Kokubo M, Mitsumori M, Ishikura S, et al. Results of breastconserving therapy for early stage breast cancer: Kyoto university experiences. Am J Clin Oncol Cancer Clin Trials. 2000;23:499-505.

49. Park CC, Mitsumori M, Nixon A, et al. Outcome at 8 years after breast-conserving surgery and radiation therapy for invasive breast cancer: Influence of margin status and systemic therapy on local recurrence. J Clin Oncol 2000;18:1668-1675.

50. Touboul E, Buffat L, Belkacemi Y, et al. Local recurrences and distant metastases after breast-conserving surgery and radiation therapy for early breast cancer. Int J Radiat Oncol Biol Phys 1999;43:25-38.

51. Freedman G, Fowble B, Hanlon A, et al. Patients with early stage invasive cancer with close or positive margins treated with conservative surgery and radiation have an increased risk of 
breast recurrence that is delayed by adjuvant systemic therapy. Int J Radiat Oncol Biol Phys 1999;44:1005-1015.

52. Obedian E, Haffty B. Negative margin status improves local control in conservatively managed breast cancer patients. Cancer J Sci Am 1999;6:28-33.

53. Pierce LJ, Strawderman MH, Douglas KR, Lichter AS. Conservative surgery and radiotherapy for early-stage breast cancer using a lung density correction: the University of Michigan experience. Int J Radiat Oncol Biol Phys. 1997;39:921-928.

54. Burke MF, Allison R, Tripcony L. Conservative therapy of breast cancer in Queensland. Int J Radiat Oncol Biol Phys. 1995;31:295-303.

55. Spivack B, Khanna MM, Tafra L, Juillard G, Giuliano AE. Margin status and local recurrence after breast-conserving surgery. Archives of Surg. 1994;129:952-956.

56. Freedman GM, Hanlon AL, Fowble BL, Anderson PR, Nicolaou $\mathrm{N}$. Recursive partitioning identifies patients at high and low risk for ipsilateral tumor recurrence after breast-conserving surgery and radiation [erratum J Clin Oncol 2002;20(24):4727]. J Clin Oncol. 2002;20:4015-21.

57. Schnitt SJ, Abner A, Gelman R, et al. The relationship between microscopic margins of resection and the risk of local recurrence in patients with breast cancer treated with breast-conserving surgery and radiation therapy. Cancer. 1994;74:1746-51.

58. Gage I, Schnitt SJ, Nixon AJ, et al. Pathologic margin involvement and the risk of recurrence in patients treated with breast-conserving therapy. Cancer. 1996;78:1921-8.

59. Cabioglu N, Hunt KK, Buchholz TA, et al. Improving local control with breast-conserving therapy: a 27-year single-institution experience. Cancer. 2005;104:20-9.

60. Horiguchi J, Iino Y, Takei H, et al. Surgical margin and breast recurrence after breast-conserving therapy. Oncol Rep. 1999;6:135-8.

61. Wazer DE, Schmidt-Ullrich RK, Ruthazer R, et al. Factors determining outcome for breast-conserving irradiation with margin-directed dose escalation to the tumor bed. Int $J$ Radiat Oncol Biol Phys. 1998;40:851-8.

62. Smitt MC, Nowels KW, Zdeblick MJ, et al. The importance of the lumpectomy surgical margin status in long-term results of breast conservation. Cancer. 1995;76:259-67.

63. Solin LJ, Fowble BL, Schultz DJ, Goodman RL. The significance of the pathology margins of the tumor excision on the outcome of patients treated with definitive irradiation for earlystage breast cancer [see comment]. Int J Radiat Oncol Biol Phys. 1991;21:279-87.

64. Peterson ME, Schultz DJ, Reynolds C, Solin LJ. Outcomes in breast cancer patients relative to margin status after treatment with breast-conserving surgery and radiation therapy: the University of Pennsylvania experience. Int J Radiat Oncol Biol Phys. 1999;43:1029-35.

65. Recht A, Come SE, Henderson IC, et al. The sequencing of chemotherapy and radiation therapy after conservative surgery for early-stage breast cancer. N Engl J Med. 1996;334:1356-61.

66. Borger J, Kemperman H, Hart A, Peterse H, van Dongen J, Bartelink H. Risk factors in breast-conservation therapy. J Clin Oncol. 1994;12:653-60.

67. Kini VR, White JR, Horwitz EM, Dmuchowski CF, Martinez AA, Vicini FA. Long term results with breast-conserving therapy for patients with early-stage breast carcinoma in a community hospital setting. Cancer. 1998;82:127-33.

68. DiBiase SJ, Komarnicky LT, Heron DE, Schwartz GF, Mansfield CM. Influence of radiation dose on positive surgical margins in women undergoing breast conservation therapy. Int $J$ Radiat Oncol Biol Phys. 2002;53:680-6.

69. Tartter PI, Kaplan J, Bleiweis I, et al. Lumpectomy margins, reexcision, and local recurrence of breast cancer. Am J Surg. 2000;179:81-5.
70. Renton SC, Gazet JC, Ford HT, Corbishley C, Sutcliffe R. The importance of the resection margin in conservative surgery for breast cancer. Eur J Surg Oncol. 1996;22:17-22.

71. Truong PT, Jones SO, Kader HA, et al. Patients with t1 to t 2 breast cancer with one to three positive nodes have higher local and regional recurrence risks compared with nodenegative patients after breast-conserving surgery and wholebreast radiotherapy. Int J Radiat Oncol Biol Phys. 2009; 73:357-64.

72. Poortmans PM, Collette L, Horiot JC, et al. Impact of the boost dose of $10 \mathrm{~Gy}$ versus $26 \mathrm{~Gy}$ in patients with early stage breast cancer after a microscopically incomplete lumpectomy: 10-year results of the randomised EORTC boost trial. Radiother Oncol. 2009;90:80-5.

73. Pittinger TP, Maronian NC, Poulter CA, et al. Importance of margin status in outcome of breast-conserving surgery for carcinoma. Surgery. 1994;116:605-9.

74. Yau TK, Soong IS, Chan K et al. Clinical outcome of breast conservation therapy for breast cancer in Hong Kong: prognostic impact of ipsilateral breast tumor recurrence and 2005 St. Gallen risk categories. Int J Radiat Oncol Biol Phys. 2007;68:667-72.

75. Bollet MA, Sigal-Zafrani B, Mazeau V, et al. Age remains the first prognostic factor for loco-regional breast cancer recurrence in young ( $<40$ years) women treated with breast conserving surgery first. Radiother Oncol. 2007;82:272-80.

76. Hardy K, Fradette K, Gheorghe R, Lucman L, Latosinsky S. The impact of margin status on local recurrence following breast conserving therapy for invasive carcinoma in Manitoba. J Surg Oncol 2008;98:399-402.

77. Rauschecker HF, Sauerbrei W, Gatzemeier W, et al. Eight-year results of a prospective non-randomised study on therapy of small breast cancer. The German Breast Cancer Study Group (GBSG). Eur J Cancer. 1998;34:315-23.

78. Jones HA, Antonini N, Hart AA, et al. Impact of pathological characteristics on local relapse after breast-conserving therapy: a subgroup analysis of the EORTC boost versus no boost trial. $J$ Clin Oncol. 2009;27:4939-47.

79. Yoshida T, Takei H, Kurosumi M, et al. Ipsilateral breast tumor relapse after breast conserving surgery in women with breast cancer. Breast 2009;18:238-43.

80. Vujovic O, Cherian A, Yu E, Dar AR, Stitt L, Perera F. The effect of timing of radiotherapy after breast-conserving surgery in patients with positive or close resection margins, young age, and node-negative disease, with long term follow-up. Int $J$ Radiat Oncol Biol Phys. 2006;66:687-90.

81. Rodriguez PA, Samper Ots PM, Lopez Carrizosa MC, et al. Early-stage breast cancer conservative treatment: high-dose-rate brachytherapy boost in a single fraction of $700 \mathrm{cGy}$ to the tumour bed. Clin Transl Oncol. 2012;14:362-8.

82. Jobsen JJ, van der Palen J, Ong F, Meerwaldt JH. Differences in outcome for positive margins in a large cohort of breast cancer patients treated with breast-conserving therapy. Acta Oncol. 2007;46:172-80.

83. Galimberti V, Maisonneuve P, Rotmensz N, et al. Influence of margin status on outcomes in lobular carcinoma: experience of the European Institute of Oncology. Ann Surg. 2011;253:580-4.

84. McCahill LE, Single R, Ratliff J, Sheehey-Jones J, Gray A, James T. Local recurrence after partial mastectomy: relation to initial surgical margins. Am J Surg. 2011;201:374-8.

85. Schroeder TM, Liem B, Sampath S, Thompson WR, Longhurst J, Royce M. Early breast cancer with positive margins: excellent local control with an upfront brachytherapy boost. Breast Cancer Res Treat. 2012;134:719-25.

86. Liu J, Hao XS, Yu Y, et al. Long-term results of breast conservation in Chinese women with breast cancer. Breast J. 2009; 15:296-8. 
87. Shimauchi A, Nemoto K, Ogawa Y, et al. Long-term outcome of breast-conserving therapy for breast cancer. Radiat Med. 2005;23:485-90.

88. Ohsumi S, Sakamoto G, Takashima S, et al. Long-term results of breast-conserving treatment for early-stage breast cancer in Japanese women from multicenter investigation. Jpn J Clin Oncol. 2003;33:61-7.

89. Vordermark D, Lackenbauer A, Wulf J, Guckenberger M, Flentje M. Local control in 118 consecutive high-risk breast cancer patients treated with breast-conserving therapy. Oncol Rep. 2007;18:1335-9.

90. Azu M, Abrahamse P, Katz SJ, Jagsi R, Morrow M. What is an adequate margin for breast-conserving surgery? Surgeon attitudes and correlates. Ann Surg Oncol. 2010;17:558-63.

91. Marudanayagam R, Singhal R, Tanchel B, O’Connor B, Balasubramanian B, Paterson I. Effect of cavity shaving on reoperation rate following breast-conserving surgery. Breast $J$. 2008;14:570-3.

92. Waljee JF, Hu ES, Newman LA, Alderman AK. Predictors of reexcision among women undergoing breast-conserving surgery for cancer. Ann Surg Oncol. 2008;15:1297-303.

93. Huston TL, Pigalarga R, Osborne MP, Tousimis E. The influence of additional surgical margins on the total specimen volume excised and the reoperative rate after breast-conserving surgery. Am J Surg. 2006;192:509-12.

94. Morrow M, Harris JR, Schnitt SJ. Surgical margins in lumpectomy for breast cancer: bigger is not better. $N$ Engl J Med. 2012;367:79-82.
95. Romond EH, Perez EA, Bryant J, et al. Trastuzumab plus adjuvant chemotherapy for operable HER2-positive breast cancer. N Engl J Med. 2005;353:1673-84.

96. Kiess AP, McArthur HL, Mahoney K, et al. Adjuvant trastuzumab reduces locoregional recurrence in women who receive breast-conservation therapy for lymph node-negative, human epidermal growth factor receptor 2-positive breast cancer. Cancer. 2012;118:1982-8.

97. Voduc KD, Cheang MCU, Tyldesley S, Gelmon K, Nielsen TO, Kennecke H. Breast cancer subtypes and the risk of local and regional relapse. J Clin Oncol. 2010;28:1684-91.

98. Arvold ND, Taghian AG, Niemierko A, et al. Age, breast cancer subtype approximation, and local recurrence after breast-conserving therapy. J Clin Oncol. 2011;29:3885-91.

99. Lowery AJ, Kell MR, Glynn RW, Kerin MJ, Sweeney KJ. Locoregional recurrence after breast cancer surgery: a systematic review by receptor phenotype. Breast Cancer Res Treat. 2012;133:831-41.

100. Lagios MD. Multicentricity of breast carcinoma demonstrated by routine correlated serial subgross and radiographic examination. Cancer. 1977;40:1726-34.

101. Holland R, Veling SH, Mravunac M, Hendriks JH. Histologic multifocality of Tis, T1-2 breast carcinomas. Implications for clinical trials of breast-conserving surgery. Cancer. 1985;56: 979-90.

102. Moher D, Liberati A, Tetzlaff J, Altman DG, The PRISMA Group. Preferred reporting items for systematic reviews and meta-analyses: the PRISMA statement. 2009 (online source). 